Thorax (1973), 28, 567.

\title{
Plasma cortisol and the use of hydrocortisone in the treatment of status asthmaticus
}

\author{
R UTH M. CAYTON and P. HOWARD
}

Department of Medicine, University of Sheffield, The Royal Hospital, West Street, Sheffield S1 3SR

\begin{abstract}
Cayton, R. M., and Howard, P. (1973). Thorax, 28, 567-573. Plasma cortisol and the use of hydrocortisone in the treatment of status asthmaticus. Plasma cortisol, intravenous synacthen tests of adrenal function, arterial blood gases, and spirometric tests of respiratory function were measured in patients with bronchial asthma during clinically stable periods and during status asthmaticus. Intravenous hydrocortisone was given in a predetermined manner in an attempt to measure the effective dose for treatment. The presence of adrenal suppression did not influence the severity of the attack nor the amount of hydrocortisone required for treatment. Clinical signs, arterial oxygen tension, forced expiratory volume, forced vital capacity, pulse rate, and blood pressure gave no indication as to which patients would respond to a single injection of aminophylline or require repeated hydrocortisone for days or weeks. The results are discussed in relation to the mechanism of bronchial asthma.
\end{abstract}

Corticosteroid drugs became available for the treatment of bronchial asthma in 1952. Twenty years later the use of hydrocortisone in the treatment of status asthmaticus remains ill-defined, doses between 100 and $1,000 \mathrm{mg}$ or more in the first 24 hours of therapy being advocated by some workers (Rees, 1967; Grant, 1966; Rebuck and Read, 1971). In this study hydrocortisone was given in a predetermined manner. The amount required to treat an acute attack of status asthmaticus was compared with clinical stigmata of its severity. Measurements of respiratory function, including arterial blood gases and the initial plasma cortisol, were made. It was hoped that one or more of these signs might help to indicate how much hydrocortisone would be required for treatment. Special attention was given to the initial plasma cortisol level before treatment was begun to determine whether those with low levels required more exogenous steroid than patients capable of maintaining a high level from their own intrinsic adrenal function.

\section{METHODS}

Plasma cortisol was measured by the method of Mattingly (1962), and the recommendations of the Medical Research Council Working Party (1971) were followed. Analyses were made using an Aminco SPF-125 spectrofluorimeter. A standard sample of plasma, Seronorm, was included with each batch of estimations.
In order to assess adrenal function, a short synacthen test was performed between 9.00 and 11.00 a.m. A venous blood sample for the basal cortisol level was taken and followed immediately by an intravenous injection of $250 \mu \mathrm{g}$ of synthetic ACTH (Synacthen, Ciba). Further blood samples were taken 30 minutes and 60 minutes later.

In the first part of the study basal plasma cortisol was measured in 53 normal subjects $(49 \cdot 2 \pm 15 \cdot 8$ years of age) consisting of medical staff, laboratory workers, and a few convalescent patients with no history of chest or endocrine disease. Short synacthen tests were performed in 14 of these persons.

Basal plasma cortisol and a short synacthen test was measured in a group of 70 unselected patients with bronchial asthma (30 male and 40 female). These estimations were made during a clinically stable phase. Bronchial asthma has been defined as widespread narrowing of the airways which varies in severity over short periods of time (Ciba Foundation Guest Symposium, 1959). All patients had a history of intermittent attacks of wheeze and breathlessness accompanied by a sharp fall in forced expiratory volume, which could be reversed by antispasmodics. Eleven patients $(37.7 \pm 14.8$ years of age) had received no previous steroid therapy, 15 patients $(46 \cdot 8 \pm 17 \cdot 1$ years of age) had had episodic courses of prednisolone but were not taking any form of steroid at the time of the synacthen test, and 44 patients were having continuous prednisolone, $28(52.5 \pm 13.8$ years of age) less than $10 \mathrm{mg}$ daily, and 16 patients $(51 \cdot 1 \pm 9 \cdot 6$ years of age) consistently more than $10 \mathrm{mg}$ prednisolone daily.

Plasma cortisol was measured in a group of patients $(63 \cdot 4 \pm 19 \cdot 1$ years of age) admitted to hospital under 
the stress of an acute medical illness. Twenty-two patients (15 male and 7 female) suffering from nonrespiratory conditions such as myocardial infarction, diabetic ketoacidosis, and acute renal failure were studied.

In the second part of the study all patients admitted to hospital in status asthmaticus between July 1971 and July 1972 were investigated. Status asthmaticus was defined as an acute attack of wheeze and breathlessness of sufficient severity to immobilize the patient and make talking difficult. The group of 35 patients (10 male and 25 female), with a mean age of $49 \cdot 0 \pm 16 \cdot 8$ years, contained several with pronounced airways obstruction but as all had bronchial asthma none was excluded on this account. Plasma cortisol was estimated on admission before any additional steroid therapy had been given, together with recordings of pulse, blood pressure, and, where possible, arterial blood gases and respiratory function. The forced expiratory volume $\left(F E V_{0.75}\right)$ and forced vital capacity (FVC) were measured with a Poulton timed spirometer (McKerrow, McDermott, and Gilson, 1960). Arterial blood gases $\left(\mathrm{PaO}_{2} ; \mathrm{PaCO}_{2}\right)$, and $\mathrm{pH}$ were measured polarographically with direct reading electrodes on a Cambridge EIL blood gas analyser. Readings of $\mathrm{PaO}_{2}$ and $\mathrm{PaCO}_{2}$ in arterial blood agreed with values expected after tonometry to within $\pm 2.0 \mathrm{mmHg}$.

Many patients had received $250 \mathrm{mg}$ of intravenous aminophylline from their family doctor before reaching hospital. Hydrocortisone therapy was started if there was no clinical improvement within one hour, or earlier if the patient's condition deteriorated. An initial dose of $200 \mathrm{mg}$ of intravenous hydrocortisone was given and this injection was repeated at fourhourly intervals as required. An intravenous infusion was set up in all patients to correct electrolyte deficiencies and facilitate the giving of repeated intravenous injections. Oxygen was administered via nasal catheters and the flow rate (2-4 litres/minute) was adjusted according to blood gas analyses. Antibiotics were prescribed if there was clinical or bacteriological evidence of a chest infection.

If after four hours there was no clinical improvement, judged by a reduction in the severity of breathlesness and a fall in pulse rate, a further injection of $200 \mathrm{mg}$ of hydrocortisone was given after repeating measurements of plasma cortisol, FEV, FVC, and arterial blood gases. This procedure was repeated after a further four hours if there was still no clinical improvement, and at four-hourly intervals as necessary until improvement was apparent. Most patients improved after one or two injections, in which case further hydrocortisone was not administered until the first signs of relapse appeared, judged by an increase in breathlessness or rise in pulse rate. It was decided in advance that if any time after the initial injection the patient's condition deteriorated, with a fall in $\mathrm{PaO}_{2}$ to less than $50 \mathrm{mmHg}$ and a rise in $\mathrm{PaCO}_{2}$ to more than $46 \mathrm{mmHg}$, he was transferred to the intensive care unit for assisted ventilation and taken out of the study. This never proved necessary and no patient was ventilated.

If the patient had been receiving prednisolone before admission to hospital, this was given again during the convalescent phase, when the clinical $\overrightarrow{ }$ condition had been stable for some time and the? patient was mobile. A short synacthen test was per- $\overrightarrow{\vec{\omega}}$ formed in the outpatient department several weeks after full recovery.

\section{RESULTS}

The 9.00 a.m. plasma cortisol for 53 normal sub-o jects was $19.5( \pm 7 \cdot 1) \mu \mathrm{g} / 100 \mathrm{ml}$, which is similar ${ }_{0}$ to other quoted values (Mattingly, 1962). Figure $1^{3}$ shows the results of short synacthen tests measured $\vec{c}$ in normal persons and 70 asthmatic patients. The 9.00 a.m. basal cortisol level in normal persons is significantly higher than the value found both in asthmatic patients taking less than $10 \mathrm{mg} \stackrel{\mathbb{D}}{-}$ prednisolone daily $(t=4 \cdot 14, \mathrm{P}<0.001)$ and in those $\overrightarrow{0}$ patients taking more than $10 \mathrm{mg}$ prednisolone $\omega \vec{\omega}$ daily $(t=4.21, \mathrm{P}<0.001)$. The 30 -minute and $60-$ minute cortisol levels found in normal persons are higher than in asthmatic patients taking predni-solone continuously. These are highly significanto in patients taking less than $10 \mathrm{mg}$ prednisolone $\frac{\odot}{\Phi}$

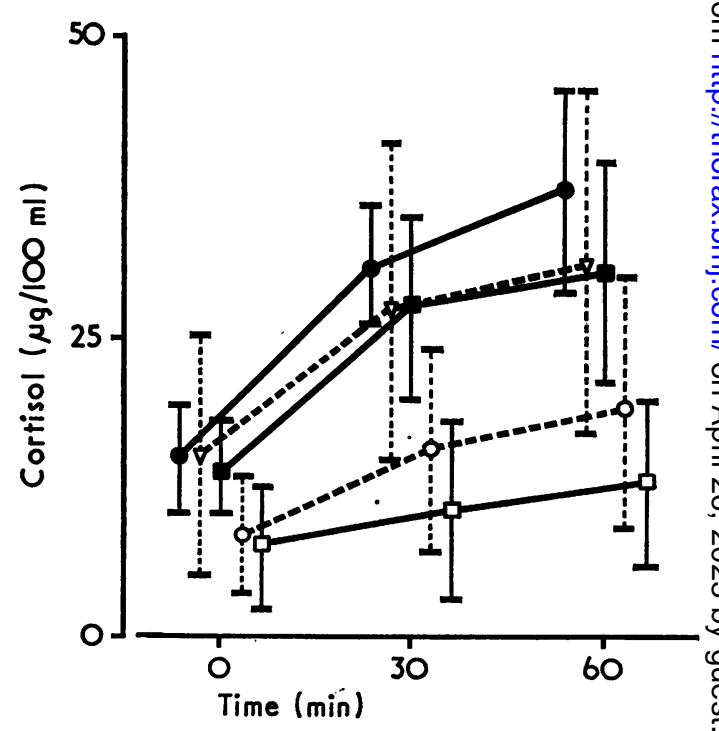

FIG. 1. Short synacthen tests measured in normal subjects $\frac{T}{0}$ and asthmatic patients: normal subject; $\nabla$ asthmaticno steroid therapy; $\square$ asthmatic-episodic steroid therapy; $\bigcirc$ asthmatic-continuous steroid therapy $(<10 \stackrel{\Phi}{\Omega}$ mg prednisolone daily); $\square$ asthmatic - continuous steroid $\bar{\sigma}$ therapy (>10 mg prednisolone daily). One standard deviation from the mean is given. 
daily at 30 minutes $(t=6 \cdot 12, \mathrm{P}<0.001)$ and at the 60 -minute level $(t=5.6, \mathrm{P}<0.001)$ and in patients on higher doses of prednisolone (30 minutes $t=8.66, \mathrm{P}<0.001$ and 60 minutes $t=7.43, \mathrm{P}<0.001$ ). Adrenal suppression as measured by the short synacthen test occurs in asthmatic patients on continuous treatment with prednisolone, irrespective of the dose.

There is a linear relationship (Fig. 2) between the 9.00 a.m. plasma cortisol and the increase in cortisol level 60 minutes after an injection of synacthen $(\mathrm{r}=0.49, t=5.06, \mathrm{P}<0.001)$. This suggests that the basal cortisol level reflects adrenal suppression and may be an indicator of the adrenal response to a physiological stress such as status asthmaticus.

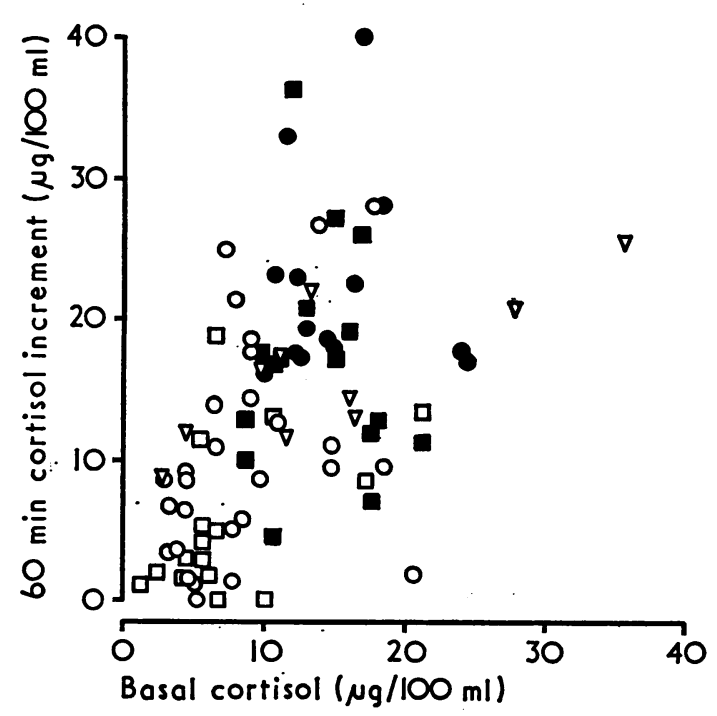

FIG. 2. Basal plasma cortisol and cortisol increment 60 minutes after intravenous synacthen injection: normal subject; $\nabla$ asthmatic-no steroid therapy; $\square$ asthmatic -episodic steroid therapy; $\bigcirc$ asthmatic-continuous steroid therapy ( $<10 \mathrm{mg}$ prednisolone daily); $\square$ asthmatic - continuous steroid therapy (>10 mg prednisolone daily).

The Table gives details of the patients studied during status asthmaticus. The age and sex of each patient are given together with the basal plasma cortisol and the best available figure in convalescence for arterial blood gases and spirometric tests of respiratory function. Figures are also given for pulse, blood pressure, and, where possible, plasma cortisol, arterial blood gases, $\mathrm{FEV}_{0.75}$, and FVC when the patient was admitted to hospital in status asthmaticus.

In Fig. 3 the admission cortisol level in patients

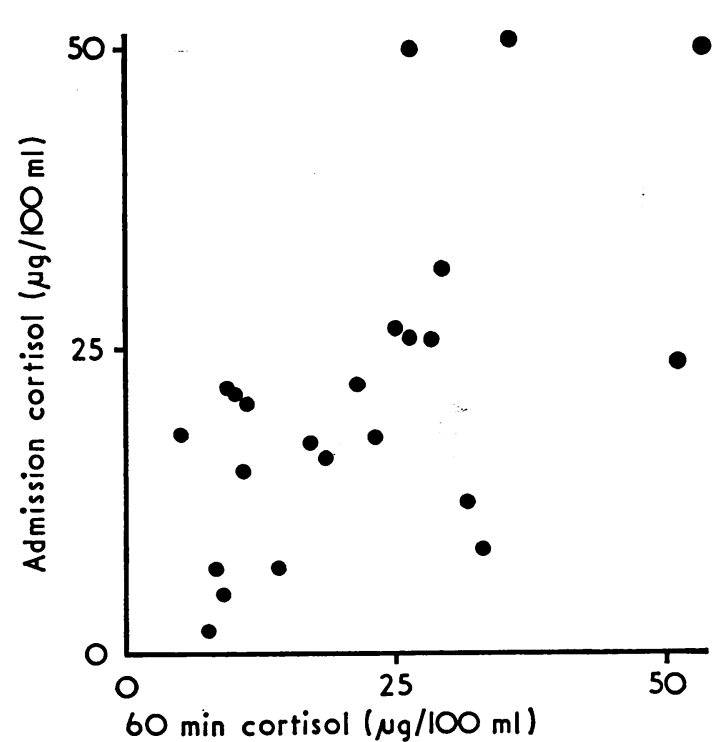

FIG. 3. Plasma cortisol measured on admission and 60 minutes after intravenous synacthen (patients with status asthmaticus).

with status asthmaticus is compared with the cortisol level achieved 60 minutes after synacthen. The synacthen test was performed in these patients several weeks after full recovery. There is a highly significant relationship between these two groups of figures $(r=0.539, t=3.2, P<0.001)$. A linear, though not quite significant, relationship has also been demonstrated between the admission plasma cortisol and the basal cortisol in the same patients. The combination of these results suggests that a low basal plasma cortisol level and poor response to synacthen, indicating adrenal suppression, reflects the limitation in the rise of plasma cortisol which occurs under the stress of status asthmaticus in patients on continuous steroid therapy.

The admission cortisol level measured in patients suffering from acute medical conditions, together with those found in status asthmaticus, are shown in Fig. 4. In the first group there is a wide range of values reaching a maximum of $158 \mu \mathrm{g} / 100 \mathrm{ml}$ in cardiogenic shock. The maximum cortisol level recorded in status asthmaticus was $50 \mu \mathrm{g} / 100 \mathrm{ml}$. Many patients on continuous steroid treatment had admission levels of less than $10 \mu \mathrm{g} / 100 \mathrm{ml}$.

The admission cortisol level was compared with clinical signs of the severity of status asthmaticus. There was no significant relationship between the initial cortisol and pulse rate, FEV, FVC or $\mathrm{PaO}_{2}$. Thus, there is no evidence to suggest that the 


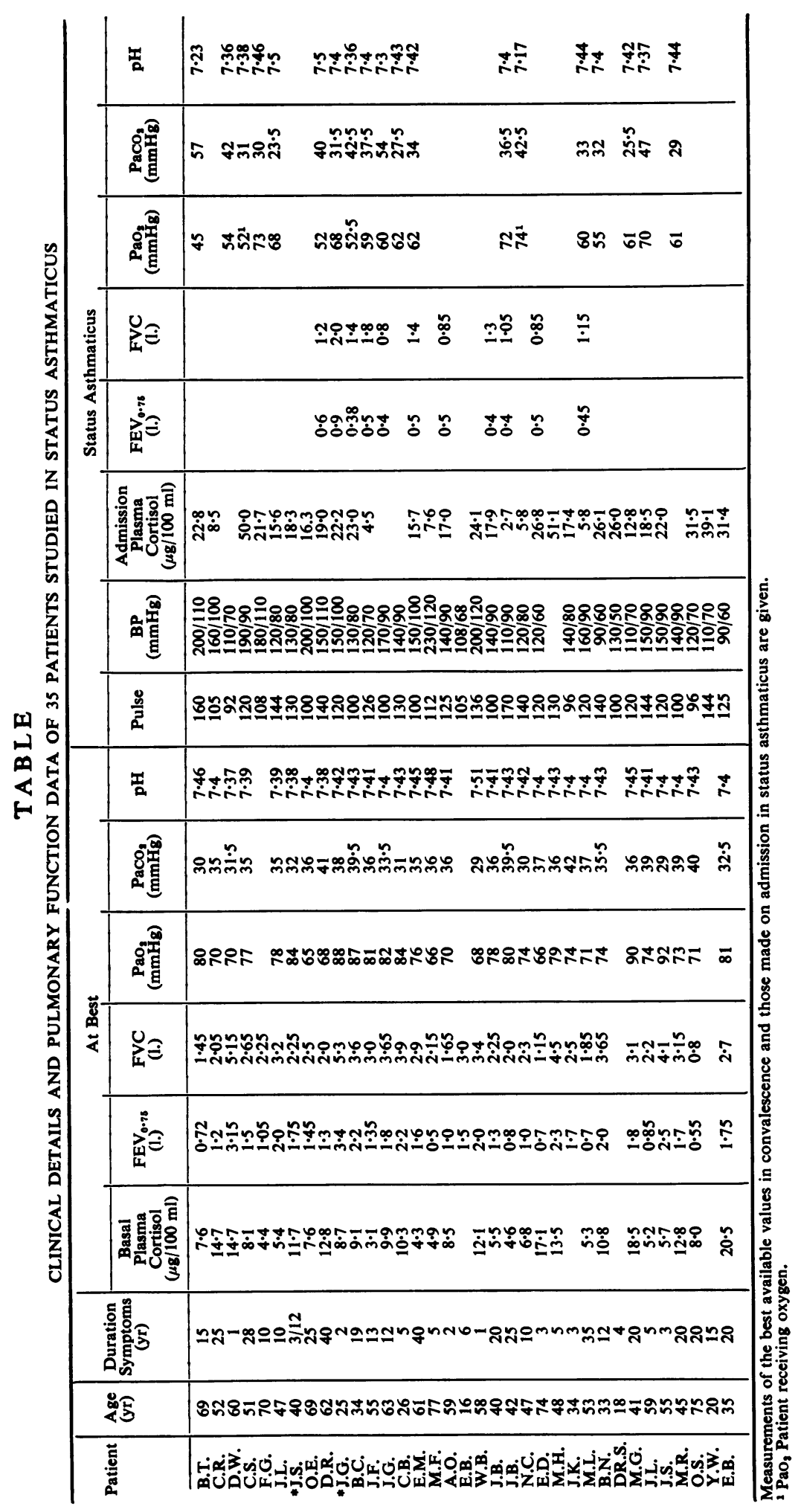




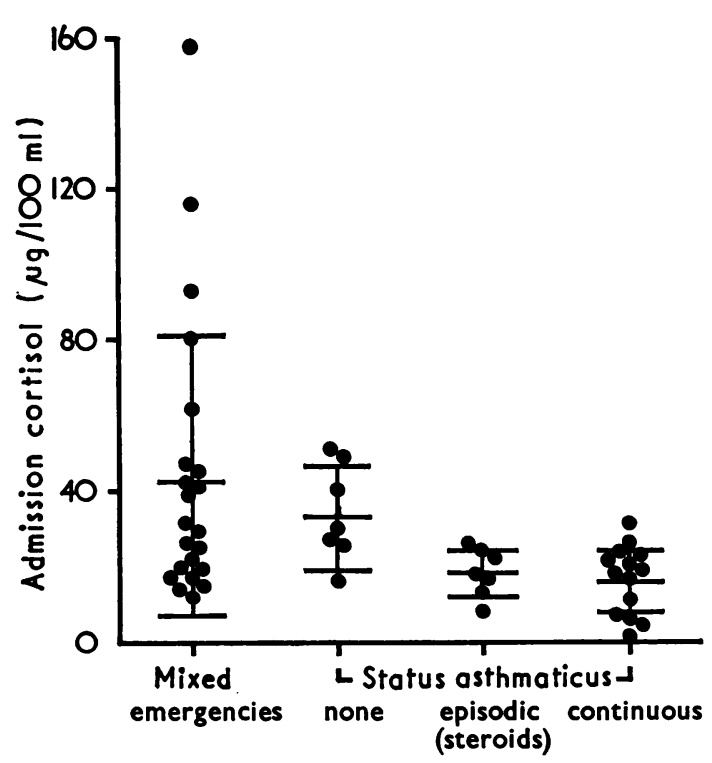

FIG. 4. Admission plasma cortisol in non-respiratory medical emergencies and status asthmaticus. One standard deviation from the mean is given.

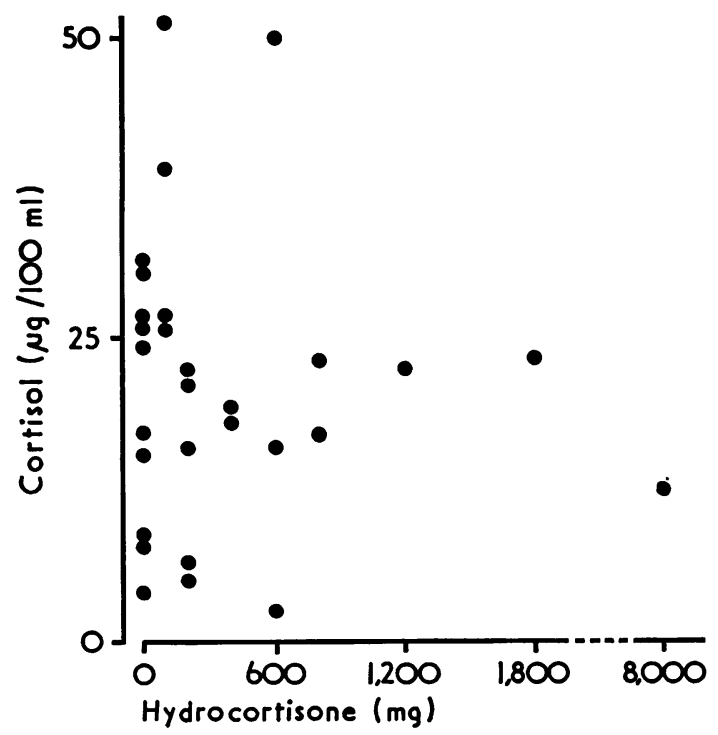

FIG. 5. Admission plasma cortisol compared with hydrocortisone required to treat the acute attack.

admission cortisol level gives any guide to the severity of status asthmaticus as judged by these parameters. Figure 5 correlates the initial level with the amount of hydrocortisone required for treatment. The relationship is not significant. Despite the presence of low cortisol levels in clinically severe asthma, many patients recovered after receiving aminophylline and no additional therapy. Other patients, with equally severe asthma and high cortisol levels, required hydrocortisone for as long as 10 days. No patient receiving continuous steroid therapy showed any evidence of adrenal failure during status asthmaticus. Hypotension was noted in two patients, neither of whom had received any previous steroid therapy. This was presumed to be due to mechanical factors prevailing in the chest at the time.

The onset and duration of an attack of status asthmaticus are unpredictable. The amount of hydrocortisone required for treatment is neither related to the admission cortisol nor to the duration of the attack. Figure 6 shows the time intervals between successive injections of hydrocortisone. Ten patients recovered after one injection of $200 \mathrm{mg}$ of hydrocortisone. Three patients required $600-800 \mathrm{mg}$ of hydrocortisone at infrequent intervals before changing to prednisolone. Their respiratory function and arterial blood gases continued to improve for some weeks. Two patients required intensive treatment with hydrocortisone for several days but once clinical improvement started recovery was rapid and complete. The plasma cortisol was not a useful guide to therapy as patients relapsed with levels ranging from $5 \mu \mathrm{g}$ to $300 \mu \mathrm{g} /$ $\mathrm{ml}$.

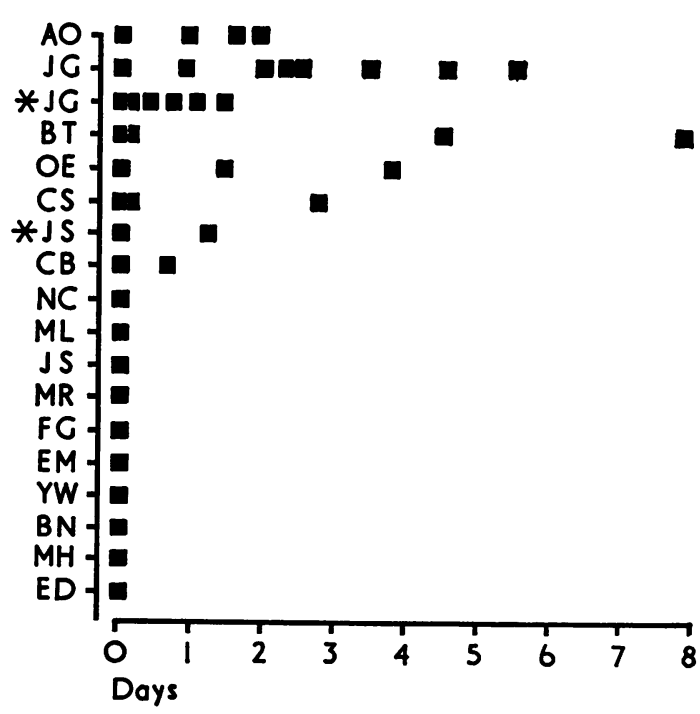

FIG. 6. Timing of hydrocortisone injections $(200 \mathrm{mg})$ during status asthmaticus (days). Each patient is represented by his initials. 


\section{DISCUSSION}

Status asthmaticus has been defined as an acute attack of asthma of more than 24 hours' duration, resistant to treatment with adrenaline. It is increasingly recognized that a patient often needs urgent medical treatment before this time interval elapses (Grant, 1966; Lancet, 1972). Tai and Read (1967) defined status asthmaticus as 'severe asthma unresponsive to the usual casualty department methods of treatment and regarded as potentially life-threatening on clinical grounds.' The American Thoracia Society (1968) regarded status asthmaticus as 'an acute asthmatic attack in which the degree of bronchial obstruction is either severe from the beginning or increases in severity and is not relieved by the usual treatment such as epinephrine or aminophylline. The life of the patient is thereby threatened. Every patient in whom there is no significant improvement within 60 minutes of receiving bronchodilator treatment should be considered in status asthmaticus'. Rees, Millar, and Donald (1968) defined status asthmaticus as 'an attack of wheezing producing dyspnoea and distress which had not responded to bronchodilator therapy given prior to admission to hospital'. These definitions differ in their emphasis. Since patients may die in less than 24 hours we have not included a time limit in our selection of patients. In terms of the severity of the dyspnoea and physiological measurements we were unable to distinguish those likely to respond to simple bronchodilators, and therefore for the purposes of this study all patients immobilized by an acute attack of asthma were included.

Status asthmaticus may be precipitated by a chest infection, allergen or emotional crisis. Some attacks occur without obvious initiating factors. The treatment of status asthmaticus is largely empirical, since no controlled trial has been carried out to compare the effects of large and small doses of hydrocortisone (Rebuck and Read, 1971). Large doses of the drug, up to $1,000 \mathrm{mg}$ in the first 24 hours of therapy, are advocated by many workers (Rees, 1967; Grant, 1966; Rebuck and Read, 1971). Patients receiving continuous steroid treatment are thought to be particularly vulnerable in status asthmaticus due to a failure to increase plasma cortisol as a result of adrenal suppression (Walsh and Grant, 1966 ; Treadwell, Savage, Sever, and Copeman, 1963). The severity of adrenal suppression is related to the daily and total dose of prednisolone administered, duration of therapy, and individual variation (Carter and James, 1970). Intravenous short synacthen tests revealed adrenal suppression in all patients on continuous dail corticosteroids. This was reflected in lower level: of plasma cortisol on admission to hospital in status asthmaticus than in patients with asthmक who had never had steroids. Despite the low level no effect on the clinical course or response to. treatment was observed. Such patients did not require larger doses of hydrocortisone to trea? the acute attack. Dwyer, Lazarus, and Hicki $\vec{\alpha}$ (1967) suggested that the plasma cortisol response to intravenous injection of hydrocortisone wass less than normal in steroid-treated patients and that this reduced response was associated with a lack of clinical improvement. Our observations and data do not support this opinion nor have we any evidence to suggest that a patient with statusD asthmaticus will not respond to treatment until specified cortisol level is achieved. Dwyer et aB (1967) mention $100 \mu \mathrm{g} / 100 \mathrm{ml}$ and Collins, Harris@ Clark, and Townsend (1970) $150 \mu \mathrm{g} / 100 \mathrm{ml}$ as the minimum plasma cortisol necessary to achieve â therapeutic response.

Admission cortisol levels in status asthmaticuso never reached levels as high as those seen in othe types of stress. The discrepancy between plasma cortisol levels of $55 \mu \mathrm{g} / 100 \mathrm{ml}$ in status asth:्ञ maticus and $155 \mu \mathrm{g} / 100 \mathrm{ml}$ in cardiogenic shock despite the latter being a terminal illness, sugges $\vec{E}$ that different forms of stress might operate through different control mechanisms.

The severity of status asthmaticus judged by clinical signs and physiological measurement dic not in any way indicate the pattern of response to? treatment, which seemed to fall into four groups $x$ Some patients required a single injection of amino욱 phylline, and others one iniection of $200 \mathrm{mg}$ of hydrocortisone. The third group required repeated hydrocortisone injections but at infrequent inter vals of several days, while group four needed in응 jections of hydrocortisone every three to foup hours.

It has been suggested that in status asthmaticus uncontrolled mast-cell degranulation occurs and that mast-cell counts are low in the bronchi of patients dying from asthma (Connell, 1971). Hist amine, serotonin, prostaglandins, and slow-reacting substance of anaphylaxis (SRS-A) released frono mast cells are thought to produce airways obstruc $\Phi$ tion by a combination of bronchial smooth muscle contraction, glandular secretion, and oedema (Orange and Austen, 1971). The relative roles of bronchomotor tone and mucous plugging in status asthmaticus are unknown.

Following death in status asthmaticus, charac뭉 teristically, the lungs show gross overinflation, theo 
small airways are plugged with a dense exudate consisting of mucus, eosinophils, and degenerate columnar epithelial cells, and there may be hypertrophy of bronchial smooth muscle (Dunnill, 1960 ; Dunnill, Massarella, and Anderson, 1969).

Bronchodilator drugs, such as the sympathomimetic amines and theophylline derivatives, act primarily on smooth muscle. In a severe attack of asthma these drugs may be insufficient to relieve airways obstruction. The anti-inflammatory action of hydrocortisone is thought to reduce capillary permeability and exudation into the bronchial lumen. In addition, it might stabilize mast cells, thus reducing the discharge of active chemicals (McCombs, 1972).

Whatever the nature of the mechanism of asthma, our results suggest that it may be rapid and selflimiting in type or of a sustained and more chronic variety. In the latter event, the patient may require continuous prednisolone. Any patient in status asthmaticus may deteriorate suddenly if mucous plugging assumes the major role in airways obstruction. In this event time spent waiting for hydrocortisone to take effect may be critical, and Grant (1971) has found a $0.5 \%$ salbutamol aerosol administered by intermittent positive pressure ventilation to be an effective measure in these circumstances.

In conclusion, adrenal suppression reflected in a reduced response to the stress of status asthmaticus does not influence the requirements of hydrocortisone to treat the acute attack. Clinical signs, measurements of respiratory function, and blood gases do not indicate which patients are likely to respond to a single injection of aminophylline or a small dose of hydrocortisone or require repeated hydrocortisone injections for several days. It is suggested that the mechanism of the attack and the pathology of the airways obstruction are the governing factors. The course of a patient with status asthmaticus cannot be predicted and treatment can be assessed only by repeated clinical observation and blood gas analyses. A clinical test is urgently required which will monitor the activity of the mechanism underlying acute bronchial asthma.

This work was supported by the Wellcome Trust and the Endowment Fund of the United Sheffield Hospitals.

\section{REFERENCES}

American Thoracic Society (1968). Management of status asthmaticus (a statement by the Committee on Therapy). American Review of Respiratory Disease, 97, 735.
Carter, Mary E., and James, V. H. T. (1970). Effect of corticotrophin therapy on pituitary-adrenal function. Annals of Rheumatic Diseases, 29, 73.

Ciba Foundation Guest Symposium (1959). Terminology, definitions, and classification of chronic pulmonary emphysema and related conditions. Thorax, 14, 286.

Collins, J. V., Harris, P. W. R., Clark, T. J. H., and Townsend, J. (1970). Intravenous corticosteroids in treatment of acute bronchial asthma. Lancet, 2, 1047.

Connell, John T. (1971). Asthmatic deaths (role of the mast cell). Journal of the American Medical Association, 215, 769.

Dunnill, M. S. (1960). The pathology of asthma, with special references to changes in the bronchial mucosa. Journal of Clinical Pathology, 13, 27.

—, Massarella, G. R., and Anderson, J. A. (1969). A comparison of the quantitative anatomy of the bronchi in normal subjects, in status asthmaticus, in chronic bronchitis, and in emphysema. Thorax, 24, 176.

Dwyer, J., Lazarus, L., and Hickie, J. B. (1967). A study of cortisol metabolism in patients with chronic asthma. Australasian Annals of Medicine, 16, 297.

Grant, I. W. B. (1966). Treatment of status asthmaticus. Lancet, 1, 363.

- (1971). The treatment of bronchial asthma. British Thoracic and Tuberculosis Association Review, 1, 43.

Lancet (1972). Editorial: Assessment and management of severe asthma. Lancet, 1, 1055.

Mattingly, D. (1962). A simple fluorimetric method for the estimation of free II-hydroxycorticoids in human plasma. Journal of Clinical Pathology, 15, 374.

McCombs, Robert P. (1972). Diseases due to immunologic reactions in the lungs (part I). New England Journal of Medicine, 286, 1186.

McKerrow, C. B., McDermott, M., and Gilson, J. C. (1960). A spirometer for measuring the forced expiratory volume with a simple calibrating device. Lancet, 1, 149.

Medical Research Council Working Party (1971). Recommended method for the determination of plasma corticosteroids. British Medical Journal, 2, 310.

Orange, R. P., and Austen, K. F. (1971). Immunological release of the chemical mediators of anaphylaxis. In: Identification of Asthma. Ciba Foundation Study Group No. 38, p. 99. Edited by R. Porter and J. Birch. Churchill Livingstone, Edinburgh and London.

Rebuck, A. S., and Read, J. (1971). Assessment and management of severe asthma. American Journal of Medicine, $51,788$.

Rees, H. A. (1967). Management of status asthmaticus. Postgraduate Medical Journal, 43, 225.

- Millar, J. S., and Donald, K. W. (1968). A study of the clinical course and arterial blood gas tensions of patients in status asthmaticus. Quarterly Journal of Medicine, 37, 541.

Tai, E., and Read, John (1967). Blood-gas tensions in bronchial asthma. Lancet, $1,644$.

Treadwell, B. L. J., Savage, O., Sever, E. D., and Copeman, W. S. C. (1963). Pituitary-adrenal function during corticosteroid therapy. Lancet, 1, 355.

Walsh, Sadie D., and Grant, I. W. B. (1966). Corticosteroids in treatment of chronic asthma. British Medical Journal, 2, 796. 